1954-57 are as follows: I, Radio Measurement and Standards (Dr. B. Decaux); II, Radio and Troposphere (Dr. R. L. Smith-Rose) ; III, Ionospheric Radio (Dr. D. F. Martyn); IV, Radio Noise of Terrestrial Origin (Mr. J. A. Ratcliffe); V, Radio Astronomy (Dr. M. Laffineur); VI, Radio Waves and Circuits (Dr. S. Silver); VII, Radio Electronics (Prof. G. A. Woonton).

The proceedings of the eleventh General Assembly are being published in eight parts available in either French or English. The first seven parts are to be devoted to the Commission activities; while Part 8, which has just been issued, contains a full account of the administrative proceedings with information on other activities of the Union (10, Part 8 (1955); pp. 125 ; obtainable from the General Secretary of the Union at 42 Rue des Minimes, Brussels; 14s. $6 d$. or 100 Belg. franes).

Although the Union does not now publish the scientific papers which are read and discussed at a General Assembly, a list of titles and authors of the 296 papers and reports submitted at The Hague meeting is given in Part 8 ; and it is to be noted that the reports of national committees will be published in full in Parts 1-7 according to the Commissions to which they refer. The Union also publishes, six times a year, an Information Bulletin, in which are recorded the activities and progress of the Union between successive General Assemblies.

The administrative proceedings (Part 8), referred to above, contains all the resolutions and recommendations adopted by the General Assembly of 1954. Among these is a recommendation accepted from Commission I that the value of $299792 \pm 2$ $\mathrm{km}$./sec. should be used in all scientific work for the velocity of electromagnetic waves in a vacuum. It was further resolved that all national laboratories in a position to do so should co-operate in making a comparison of standards of power measurement at frequencies of 3,000 and $10,000 \mathrm{Mc} / \mathrm{s}$.

A full report of the discussions which led up to these recommendations is contained in Part 1 of the proceedings, which was published a few months ago (10, Part 1 (1955); pp. 57; 8s. 8d. or 60 Belg. francs). This Part 1 contains all the national reports submitted to Commission I, together with the minutes of the meetings of the Commission at The Hague and the resolutions submitted to the General Assembly for adoption. In response to a request received from the International Radio Consultative Committee, it was recommended that members of the International Scientific Radio Union should make observations on the service areas and mutual interference zones of standard frequency transmissions, and also on the type of modulation used by the stations at present in operation. A study of the results of such observations should be of great assistance in the establishment and operation of an effective standard frequency and time service on a world-wide basis.

Among the other activities of the Union reported in Part 1 of the proceedings is an account of the meetings of the committee appointed to consider the programme of work for the forthcoming International Geophysical Year during 1957-58, and brief accounts of the meetings of the Mixed Commission on the Ionosphere and of the Joint Commission on Radio Meteorology held in 1954. The Union committee on the International Geophysical Year has considered various matters relating to the proposed programmes of observations in connexion with meteorology, aurora, ionospheric absorption and 'winds', radio star scintillations, meteors, atmospherics and terrestrial noise. It has also given preliminary consideration to the question of presentation and publication of the results obtained, and made recommendations on all these matters to the international committee on the International Geophysical Year, which will meet again shortly to formulate the recommended world-wide programme.

It is clear from the two parts ( 1 and 8 ) of the proceedings already available that they comprise excellent surveys of the relevant fields of radio research, fully documented with references to the original scientific published papers, and the appearance of the remaining parts dealing with the work of Commissions II-VII will be awaited with interest by students and research workers in the field of scientific radio.

R. I. SMITH-RosE

\section{PRODUCTION AND MEASUREMENT OF ULTRA-HIGH VACUA}

QEFORE 1950, pressures of the order of $10^{-7} \mathrm{~mm}$. of mercury were considered high vacua, and although, undoubtedly, lower pressures were obtained, it was not possible to measure them because the most sensitive vacuum gauges were no longer reliable at such low pressures. To-day, it is possible to produce and measure pressures of $10^{-8}-10^{-11} \mathrm{~mm}$. of mercury, to estimate pressures as low as $10^{-12} \mathrm{~mm}$. and, in the case where interest is concentrated on the chemically active gases present in the space to be evacuated, to estimate partial pressures of these gases of the order of $10^{-14} \mathrm{~mm}$.

A brief but interesting review of these recent developments, together with a summary of the operation of basic pumping apparatus, is given by Dr. J. A. Becker in the January number of the Bell Laboratories Record (33, No. 1; 1955). The combination of fore-pump, mercury diffusion pump and cold trap enables pressures of less than $10^{-8} \mathrm{~mm}$. to be reached. With the Mcleod gauge, pressures down to about $10^{-6} \mathrm{~mm}$. can be accurately measured, and with the ionization gauge, introduced in 1916, lower pressures by extrapolation can be determined. The ionization gauge fails, however, when the pressure reaches $10^{-8} \mathrm{~mm}$., and work since 1950 has shown that ionizing currents, produced by soft X-rays striking the plate of the gauge, and the emission of photo electrons together with an electron current that reaches the plate even when the plate is at a negative potential with respect to the cathode, which are independent of the pressure, constitute the limiting factors. Bayard and Alpert have proposed an arrangement by which these currents may be minimized. The plate is reduced to a fine wire and surrounded by a cylindrical grid with the filament placed outside the grid. With this modified type of ionization gauge, pressures of $10^{-11} \mathrm{~mm}$. of mercury have been measured.

To attain these ultra-high vacua it becomes important to know the amount of, and sources of, residual gas present in the system to be evacuated, and Dr. Becker describes four such sources. They are the release of gas from the cold trap; the diffusion of dissolved gases out of the glass and metal parts of the system; the release of gases adsorbed 
on the surfaces of the parts of the system and the diffusion in time of gases from the atmosphere through the glass envelope. Some recent studies of gettering phenomena and observations on the adsorption of gases on clean tungsten, tantalum and molybdenum surfaces conducted in the Bell Laboratories in connexion with vacua of $10^{-12}-10^{-14} \mathrm{~mm}$. are briefly referred to. Evaporated films, however, do not pump rare gases like helium and neon, and to remove thern use is made of the ion gauge, which, in addition to its use as a manometer, can also act as a pump. Its speed of pumping is much lower than that of a mereury diffusion pump or of evaporated films, but it has the particular advantages that there is no lower pressure-limit to its pumping action and that it can be incorporated in the tube being evacuated.

\section{COUNTING AND SIZING OF PARTICLES WITH THE FLYING- SPOT MICROSCOPE}

By D. CAUSLEY and Prof. J. Z. YOUNG, F.R.S. Department of Anatomy, University College, London M 1 Ecopic particles by the use of the flying-spot microscope have been tested with blood, nerve cells, dust particles and prepared standard sprays. The system involves scanning the preparation with twin spots of light, differently polarized, and passing the pulses generated by twin photocells to an anticoincidence circuit and then to a counting unit. The circuit ensures that a count is registered only on the sweep at which one of the spots crosses the particle; when both cross it the pulses are made to cancel each other ${ }^{1,2}$. Every time that a pulse passes to the eounter, the spot on the display tube is made more intense. This provides a visual display that shows which particles have been counted (Fig. 1).

Red cell counts. Red cell counts were carried out with the co-operation of Prof. M. Maizels. Twenty

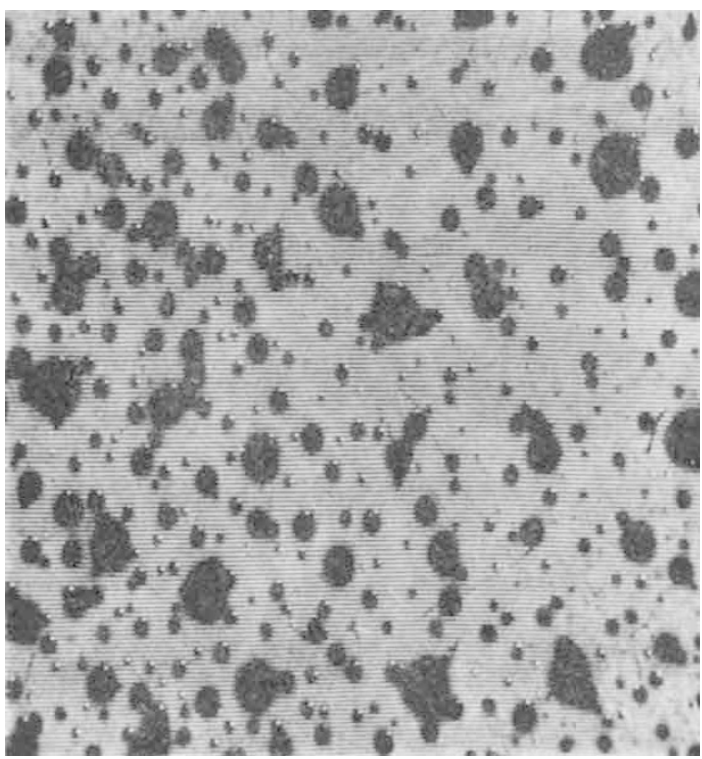

Fig. 1. View of test slide with machine presumed to be counting all particles. The bright spots indicate that a pulse has been passed to the counter
Table 1. HUMAN RED CORPUScle CoUnts (M/c. mm.) Columns 2 , 3 and 4 are visual counts, 5 and 6 machine counts. Counts 3 and 4 were made by a different observer to count 2 . The counts in columns 3 and 5 and 4 and 6 were from the same fllings of the slide.

\begin{tabular}{|c|c|c|c|c|c|}
\hline $\begin{array}{c}\text { (1) } \\
\text { Sample }\end{array}$ & $\begin{array}{c}\text { (2) } \\
\text { Visual } \\
\text { Hospital }\end{array}$ & $\begin{array}{c}\text { (3) } \\
\text { Visual } \\
\text { Lab. 1 }\end{array}$ & $\begin{array}{c}\text { (4) } \\
\text { Visual } \\
\text { Lab. 2 }\end{array}$ & $\begin{array}{c}\text { (5) } \\
\text { Machine } \\
1\end{array}$ & $\begin{array}{c}(6) \\
\text { Machine } \\
2\end{array}$ \\
\hline 1 & $3 \cdot 9$ & $3 \cdot 8$ & $3 \cdot 6$ & $3 \cdot 9$ & $3 \cdot 8$ \\
\hline 2 & $5 \cdot 1$ & $4 \cdot 4$ & $5 \cdot 3$ & $4 \cdot 5$ & $5 \cdot 3$ \\
3 & $4 \cdot 1$ & $4 \cdot 0$ & $3 \cdot 8$ & $3 \cdot 7$ & $4 \cdot 0$ \\
4 & $2 \cdot 5$ & $2 \cdot 4$ & $2 \cdot 6$ & $3 \cdot 0$ & $3 \cdot 0$ \\
5 & $1 \cdot 2$ & $1 \cdot 1$ & $1 \cdot 1$ & $1 \cdot 3$ & $1 \cdot 3$ \\
6 & $3 \cdot 2$ & $3 \cdot 1$ & $3 \cdot 2$ & $3 \cdot 0$ & $3 \cdot 3$ \\
7 & $3 \cdot 6$ & $3 \cdot 7$ & $3 \cdot 4$ & $3 \cdot 5$ & $3 \cdot 5$ \\
8 & $3 \cdot 5$ & $3 \cdot 8$ & $3 \cdot 4$ & $3 \cdot 5$ & $3 \cdot 6$ \\
9 & $3 \cdot 9$ & $3 \cdot 8$ & $3 \cdot 8$ & $3 \cdot 7$ & $3 \cdot 7$ \\
10 & $4 \cdot 5$ & $4 \cdot 5$ & $4 \cdot 5$ & $4 \cdot 8$ & $4 \cdot 6$ \\
11 & $4 \cdot 8$ & $4 \cdot 7$ & $4 \cdot 8$ & $4 \cdot 6$ & $4 \cdot 6$ \\
12 & $4 \cdot 7$ & $4 \cdot 4$ & $4 \cdot 3$ & $4 \cdot 4$ & $4 \cdot 4$ \\
13 & $4 \cdot 9$ & $4 \cdot 8$ & $4 \cdot 7$ & $4 \cdot 7$ & $4 \cdot 7$ \\
14 & $4 \cdot 6$ & $4 \cdot 7$ & $4 \cdot 5$ & $4 \cdot 7$ & $4 \cdot 7$ \\
15 & $3 \cdot 3$ & $3 \cdot 3$ & $3 \cdot 3$ & $3 \cdot 4$ & $3 \cdot 3$ \\
16 & $6 \cdot 7$ & $7 \cdot 0$ & $6 \cdot 8$ & $7 \cdot 1$ & $6 \cdot 2$ \\
17 & $4 \cdot 2$ & $4 \cdot 1$ & $4 \cdot 1$ & $4 \cdot 1$ & $4 \cdot 1$ \\
18 & $4 \cdot 5$ & $4 \cdot 3$ & $4 \cdot 2$ & $4 \cdot 2$ & $4 \cdot 2$ \\
19 & $4 \cdot 2$ & $4 \cdot 2$ & $4 \cdot 2$ & $4 \cdot 2$ & $4 \cdot 2$ \\
20 & $5 \cdot 2$ & $5 \cdot 2$ & $5 \cdot 2$ & $4 \cdot 9$ & $5 \cdot 0$ \\
\hline
\end{tabular}

samples of blood were counted by the routine visual method in the hospital laboratory. Two sub-samples were taken from each blood and counted both visually and by the machine in our Department. The visual counts were made with the standard method of recording corpuscles that lie upon the linos of a hæmocytometer. The machine counts were made on a microscopic field of known area, including about six hundred corpuscles. Each machine count was repeated three times on the same field, and the mean taken.

Table 1 and an analysis of variance show that although the bloods differed greatly, there were no consistent differences resulting from the methods of counting, whether by the hospital laboratory, a second visual observer or the machine.

The replication of the visual and machine counts enabled estimates of variance to be made; there were no significant differences, but the machine variance was possibly the smaller. The standard deviation is about $0.17 \mathrm{M} / \mathrm{c} . \mathrm{mm}$. by both methods, giving a coefficient of variation of about 4 per cent.

We may conclude that machine blood counts, though much quicker, are as accurate and consistent as visual ones-perhaps more so. The time involved in preparation of the specimen is equal in the two cases, but the counting takes 4 sec. with the machine, at least $4 \mathrm{~min}$. for the visual observer. The repetition of counts on a given field, which is so quickly undertaken by the machine, gives a further protection against error.

Table 2. Counts of THE NUMBer of Particles ReCORDed bY THE MACHINE AND THE TOTAL OF NUCLEI (AND NUCLEAR FRAGMENTS) MADE BY VISUAL OBSERVATION

Each count is for a strip $500 \mu$ wide extending from the pial surface to the white matter of the rat's cerebral cortex, stained with gallo-

$\begin{array}{cc}\begin{array}{c}\text { cyanin } \\ \text { Total particles } \\ \text { Machine count }\end{array} & \begin{array}{c}\text { Nuclei } \\ \text { Visual count }\end{array} \\ 1,336 & 1,253 \\ 1,183 & 1,220 \\ 1,172 & 1,303 \\ 1,164 & 1,181 \\ 1,410 & 1,424 \\ 1,044 & 1,389 \\ 1,197 & 1,170 \\ 1,296 & 1,357 \\ 1,464 & 1,503 \\ 1,389 & 1,357 \\ 1,289 & 1,242 \\ 1,018 & 1,048 \\ 1,315 & 1,258 \\ 1,240 & 1,104 \\ 1,349 & 1,087 \\ 1,372 & 1,069\end{array}$

